\title{
Concurrent presentation of thyroid storm and diabetic ketoacidosis: a systematic review of previously reported cases
}

\author{
Devarajan Rathish ${ }^{*}$ (i) and Senuri Karalliyadda
}

\begin{abstract}
Background: Simultaneous development of thyroid storm and diabetic ketoacidosis (DKA) is a rare condition. The review aims to summarise its clinical presentation, investigation findings and treatment options.

Methods: Databases and reference lists of the selected articles were searched for case reports in English which describe concurrent presentation of thyroid storm and diabetic ketoacidosis. CARE guidelines were used for the quality assessment of the selected articles.

Results: Twenty-six cases from twenty-one articles were selected out of 198 search results. Western Pacific, and American regions contributed to $77 \%$ of the cases. Females were most affected (88\%). Features of Graves' disease like hyperthermia and tachycardia, gastrointestinal and neuro-psychiatric disturbances were the common clinical presentations. In most of the cases, previous diagnosis of diabetes mellitus preceded that of Graves' disease (46\%). Among patients having their drug compliance reported, all had poor compliance to their routine anti-thyroid (9/9) and anti-diabetic (2/2) agents. Moreover, in all cases where $\mathrm{HbA}_{1 \mathrm{C}}(7 / 7)$ and $\mathrm{T4}(16 / 16)$ were measured, the results were elevated and where TSH (17/17) was measured, the results were low. The recommended treatment for DKA and thyroid storm was used in most cases and methimazole was the thionamide of choice in the latest four cases reported. All cases survived except four (15\%).
\end{abstract}

Conclusions: Concurrent presentation of thyroid storm and diabetic ketoacidosis is rare but life-threatening. Therefore, efforts should be made to maximise patient compliance to anti-thyroid and anti-diabetic agents in treating such patients.

Keywords: Thyrotoxic crisis, Thyroid crisis, Diabetes mellitus, Anti-thyroid drugs, Anti-diabetic drugs, Case reports

\section{Background}

Diabetic ketoacidosis (DKA) is a serious metabolic state due to lack of insulin, and it is usually seen among patients with type 1 diabetes mellitus [1]. DKA is characterised by hyperglycaemia, ketosis and metabolic acidosis [2]. Females had higher prevalence of DKA [3]. Although, age 18 to 44 years is more prone for DKA, the extremes of ages show higher mortality in DKA [1]. The most common precipitating factors for DKA in the developed countries were poor adherence to insulin therapy, infection and newly diagnosed diabetes mellitus. However, infections and poor access to care were the

\footnotetext{
* Correspondence: rathishdeva@gmail.com

Department of Pharmacology, Faculty of Medicine and Allied Sciences,

Rajarata University of Sri Lanka, Saliyapura 50008, Sri Lanka
}

most common precipitating factors in developing countries [4]. A systematic review reported a prevalence of $0-128$ per 1000 people and an incidence of $0-56$ per 1000 person-years for DKA [3].

Thyroid storm (TS) or thyrotoxic crisis or thyroid crisis is "the extreme manifestation of thyrotoxicosis, presenting as a clinical syndrome of multi-organ dysfunction, with or without a precipitating cause" [5]. It often follows sudden cessation of antithyroid drugs, surgeries, trauma, acute illnesses, drug reactions, parturition, use of iodinated contrast medium and radioiodine therapy but, it can also occur without an apparent cause [6]. Females are more prone to develop TS, and all age groups are affected [7]. TS related mortality was found to be associated with shock, intravascular coagulation and multi-organ failure

(c) The Author(s). 2019 Open Access This article is distributed under the terms of the Creative Commons Attribution 4.0 International License (http://creativecommons.org/licenses/by/4.0/), which permits unrestricted use, distribution, and reproduction in any medium, provided you give appropriate credit to the original author(s) and the source, provide a link to the Creative Commons license, and indicate if changes were made. The Creative Commons Public Domain Dedication waiver (http://creativecommons.org/publicdomain/zero/1.0/) applies to the data made available in this article, unless otherwise stated. 
[8]. The incidence of thyroid storm was reported as 0.2 per 100,000 population per year from Japan [9].

Potenza M and colleagues (2009) stated that the variations in "insulin secretion, insulin clearance, gluconeogenesis, glycogen synthesis, glucose oxidation, nonoxidative glucose metabolism, adipokine signalling, and lipid oxidation" would increase blood glucose levels and insulin resistance among patients with excessive thyroid hormone [10]. The above mechanism could disturb the patient's diabetic control and lead to DKA which in-turn would cause thyroid storm [10]. We aim to systematically review cases reported on concurrent presentation of TS and DKA concerning its presentation, investigations and management. In 2009 (9 cases) and 2017 (18 cases), two separate summaries on concurrent presentation of TS and DKA were reported along with similar case reports [10, 11]. However, this systemic review includes additional cases and an in-depth analysis.

\section{Methods}

\section{Eligibility criteria}

The review included all case reports published on concurrent presentation of TS and DKA. The Burch-Wartofsky Point Scale (BWPS) [12] and the Japan Thyroid Association criteria (JTA) [13] were used to define TS and its severity. The severity of DKA was defined using the diagnostic criteria for diabetic ketoacidosis [1]. In cases where an arterial blood gas analysis on admission was not reported, the diagnosis of DKA by the relevant authors of the case report was considered. Reports in non-English language were excluded. Reports were not excluded based on the year of publication or patient population.

\section{Information sources and search strategy}

The research was done in September 2018. Electronic databases and grey literature were searched using a string of keywords (Table 1). PubMed (Advanced search) [14], Science Direct (Advanced search) [15], Trip (Search) [16], The Cochrane Library (Advanced search) [17], Google Scholar (Advanced search) [18] and Google search (verbatim) [18] were searched. Further, the reference lists of the selected reports were searched for relevant cases. $\mathrm{MeSH}$ and other related terms were used to obtain optimum data.

\section{Study selection}

Both DR and SK were involved in study selection. DR performed a comprehensive literature search. SK independently screened the titles and abstracts of all identified studies for selection, according to the inclusion criteria. The selected study was independently reviewed by DR to confirm the eligibility.
Table 1 Keywords for databases and the number of search results

\begin{tabular}{|c|c|}
\hline Database and Keywords & $\begin{array}{l}\text { No of search } \\
\text { results }\end{array}$ \\
\hline $\begin{array}{l}\text { PubMed (Advanced search) } \\
\text { (((((()"thyroid storm"[Title/Abstract]) OR Thyroid } \\
\text { storm[MeSH Terms]) OR "thyroid crisis"[Title/Abstract]]) OR } \\
\text { "thyroid crisis"[MeSH Terms]) OR "thyrotoxic crisis"[Title/ } \\
\text { Abstract]) OR thyrotoxic crisis[MeSH Terms])) AND } \\
\text { ((((“diabetic ketoacidosis"[Title/Abstract]) OR "diabetic } \\
\text { ketoacidosis"[MeSH Terms]) OR "ketoacidosis"[Title/ } \\
\text { Abstract]) OR ketoacidosis[MeSH Terms]) }\end{array}$ & 41 \\
\hline $\begin{array}{l}\text { Science Direct (Advanced search) } \\
\text { (Thyroid storm OR thyroid crisis OR thyrotoxic crisis) AND } \\
\text { (Diabetic ketoacidosis OR ketoacidosis) }\end{array}$ & 9 \\
\hline $\begin{array}{l}\text { Trip (Search) } \\
\text { (Thyroid storm OR thyroid crisis OR thyrotoxic } \\
\text { crisis)(Diabetic ketoacidosis OR ketoacidosis) }\end{array}$ & 23 \\
\hline $\begin{array}{l}\text { The Cochrane Library (Advanced search) } \\
\text { Thyroid storm OR thyroid crisis OR thyrotoxic crisis (Title } \\
\text { Abstract Keyword) AND Diabetic ketoacidosis OR } \\
\text { ketoacidosis (Title Abstract Keyword) }\end{array}$ & 1 \\
\hline $\begin{array}{l}\text { Google Scholar (Advanced search) } \\
\text { allintitle: (Thyroid storm OR thyroid crisis OR thyrotoxic } \\
\text { crisis) AND (Diabetic ketoacidosis OR ketoacidosis) }\end{array}$ & 1 \\
\hline $\begin{array}{l}\text { Google Search (Verbatim) } \\
\text { (Thyroid storm OR thyroid crisis OR thyrotoxic crisis) AND } \\
\text { (Diabetic ketoacidosis OR ketoacidosis) }\end{array}$ & 123 \\
\hline Total & 198 \\
\hline
\end{tabular}

\section{Data collection process, data items and data analysis}

Demographic data, clinical presentation, investigation findings and the management plan were extracted from the selected studies. The units of measurements were presented in SI units. The data were analysed using Microsoft Excel (Additional file 1). Descriptive statistics were used to describe the data. The quality of the case reports was assessed using the CARE guidelines [19]. A score of one was given for each item outlined in the CARE guidelines with a maximum score of 30 for a case report. This systematic review was reported according to the Preferred Reporting Items for Systematic survey and Meta-Analysis (PRISMA) statement [20] (Additional file 2).

\section{Results}

\section{Selected case reports}

A total of 198 results were found from databases (Table 1), and 4 reports were selected from the reference lists. Following the exclusion of duplicates, 152 articles underwent title and abstract screening out of which 112 articles were excluded due to irrelevance to the review objective. One report was excluded due to unavailability of full-text [21]. Another 11 reports were excluded as these were in Swedish [22], Serbian [23], Russian [24, 25], Japanese [26, 27] and German [28-32] languages. The full-texts of the remaining 28 reports were studied, and 7 were excluded due to 
mismatch with the selection criteria (absence of thyroid storm - 4, absence of DKA - 3). Finally, 21 reports were subsequently selected which had 26 cases [10, 11, 33-51] (Fig. 1). The mean score for the quality assessment of the selected 26 cases was 19.2 ( $\mathrm{SD} \pm 3.6)$. The minimum and the maximum score achieved were 14 and 25 , respectively. Summary of scores for each item of the CARE checklist is given in Additional file 3.

\section{Characteristics of the selected studies}

Additional file 1 contains extracted data from the 26 cases selected for this review. Eleven cases were reported from Western Pacific region (42\%), nine from the region of Americas (35\%), three each from European and Eastern Mediterranean regions (each 12\%). There were no cases reported from the African or the South-East Asian region. The highest number of cases were reported from the United States of America $(n=11)$, followed by Taiwan $(n$ $=4)$, Japan $(n=3)$, United Kingdom $(n=3)$, Saudi Arabia $(n=2)$, Republic of Korea $(n=1)$, New Zealand $(n=1)$ and Spain $(n=1)$. The first case study was found to be reported by Hanscom and Ryan in 1957 from the United States of America [33]. The latest case was reported by
Cheng ET at el. in 2017 from Taiwan [49]. The mean age of the patients was 39.69 years (SD 19.94), with an age range of $16-81$ years. There were 23 females $(88 \%)$ and 3 males (12\%). Two cases were less than 18 years and were from the Republic of Korea [39] and Taiwan [49]. The nationality of the patients was reported in only two cases. Those were Afghanis and Chinese from the Saudi Arabia [47] and New Zealand [36] respectively.

\section{Clinical presentations}

More than half of the patients presented with either gastrointestinal (81\%) or neurological symptoms (54\%). Also, general features like fever, heat intolerance, lethargy, sweating, weakness and weight loss were seen in $73 \%$ of the cases. Other presenting complaints are shown in Table 2.

\section{Summary of results of Burch-Wartofsky point scale (BWPS) for the diagnosis of thyroid storm}

All cases had a documented initial heart rate of $>100$ beats per minute, and $73 \%(19 / 26)$ of the cases had an initial temperature of $>37.5^{\circ} \mathrm{C}$. More than half of the cases had central nervous system disturbance $(58 \%$ - 15/26),

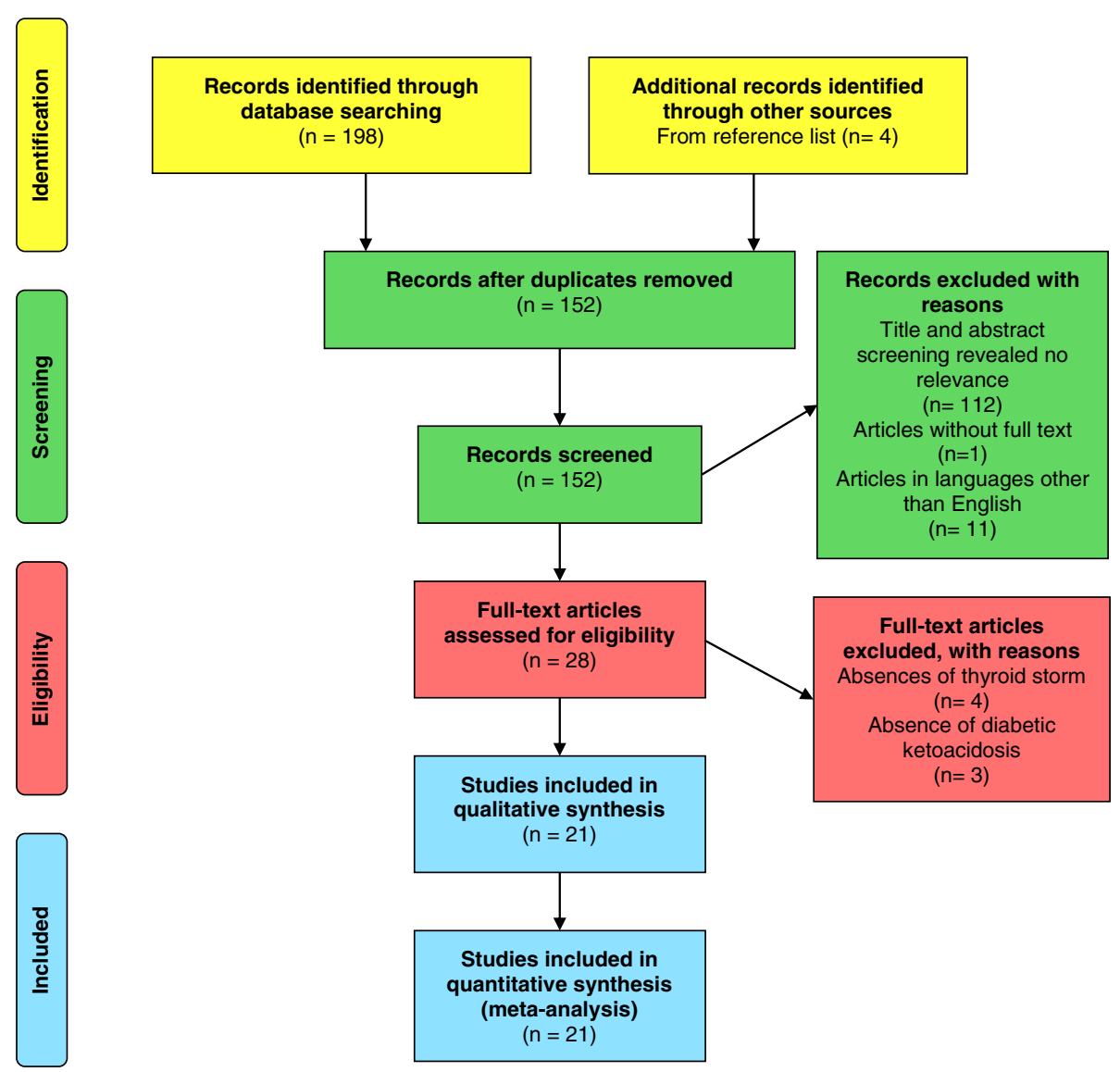

Fig. 1 Flow diagram showing the selection process of articles for this review, according to PRISMA 2009 
Table 2 Presenting complaints of the patients with both thyroid storm and diabetic ketoacidosis

\begin{tabular}{lc}
\hline Presenting complaint according to organ systems & Frequency out of 26 (\%) \\
\hline Gastrointestinal (abdominal fullness, abdominal pain, anorexia, diarrhoea, epigastric pain, nausea, polyphagia, vomiting) & 21 (81) \\
General (fever, heat intolerance, lethargy, sweating, weakness, weight loss) & $19(73)$ \\
$\begin{array}{l}\text { Neurological/ psychological (altered mental status, anxiety, confusion, delirium, distressed, dizziness, irritability, slurred } \\
\text { speech, unconscious) }\end{array}$ & $14(54)$ \\
Cardiovascular (palpitation) & $10(39)$ \\
Dehydration (dry mouth, polydipsia) & $10(39)$ \\
Renal (polyuria) & $9(35)$ \\
Respiratory (chest pain, cough, dyspnoea, sore throat) & $9(35)$ \\
Musculoskeletal (back pain, inter-scapular pain, shoulder pain) & $2(8)$
\end{tabular}

gastrointestinal-hepatic dysfunction (92\% - 24/26) and a probable precipitating event $(54 \%-14 / 26)$. Out of those cases reporting of central nervous system dysfunction, mild, moderate and severe manifestations were seen in $47 \%$ (7/15), $40 \%(6 / 15)$ and $13 \%(2 / 15)$ cases respectively. Out of those who had gastrointestinal-hepatic dysfunction, the majority had moderate manifestation (96\% - 23/24) and one patient had severe manifestation. Atrial fibrillation and heart failure were reported in 6 and 2 cases respectively. Poor compliance with the anti-thyroid drug was the most common precipitating event $(64 \%-9 / 14)$. Influenza A $(n=2)$, under treated Grave's disease (GD) $(n=2)$, automobile accident $(n=1)$, dilation and curettage $(n=1)$, post-surgery $(n=1)$, pregnancy and prepartum hypothyroidism treated with desiccated thyroid $(n=1)$ and septicaemia $(n=1)$ were the other possible precipitating events for TS. The mean (SD) score for BWPS was 62.3 (10.0) with a range of 40 to 80 . The reported score and the reviewers' score for BWPS did not tally in two case reports $[39,51]$. One received extra 10 points for a probable precipitating event (poor drug compliance) [51] while the other did not report the breakdown of the scores [39].

\section{Summary of results of Japan thyroid association criteria for the diagnosis of thyroid storm}

In all cases where T4 (16/16) were measured, the results were elevated whereas, 83\% (5/6) of T3 levels were elevated. In all cases where TSH (17/17) was measured, the results were low. Most of the cases were graded as TS1 first combination (46\% - 12/26), while 39\% (10/26) were TS2 alternative combination, $12 \%(3 / 26)$ were TS2 first combination and the grading was unable to be performed in one case report.

\section{Summary of results of the diagnostic criteria for diabetic ketoacidosis}

The mean serum bicarbonate and the anion gap fulfilled the "severe" category of DKA (Table 3). The mean arterial $\mathrm{pH}$ fulfilled the "moderate" category of DKA. Out of the cases reporting serum $(n=8)$ and urine $(n=14)$ ketones, all were found to be positive (100\%). Out of the cases reporting the mental status, drowsiness was seen in $69 \%(9 / 13)$ while $15 \%(2 / 13)$ of the cases were alert and $8 \%(1 / 13)$ each had stupor and coma. Majority of the cases were having severe DKA $(58 \%$ - 15/26), followed by moderate DKA in $27 \%(7 / 26)$, mild DKA in $12 \%(3 / 26)$ and the severity was unable to be assessed in one patient. Moreover, $\mathrm{HbA}_{1 \mathrm{C}}$ was reported in seven patients and the mean $(\mathrm{SD}) \mathrm{HbA}_{1 \mathrm{C}}$ was 11.7 (2.4) \% with a range of 7.7 to $14.6 \%$. Details of other investigations including antibody levels are summarized in Additional file 1.

\section{Past medical history}

Past history of DKA was reported in two cases from Japan [34] and Spain [41]. Diabetes mellitus (58\% - 15/26), GD $(35 \%$ - 9/26) and hypertension $(8 \%$ - 2/26) were the three most common past medical illnesses (Additional file 1). Five patients were reported to have a past history of both diabetes mellitus and GD. Diabetes mellitus was diagnosed before GD in 12 cases (46\%), GD before diabetes mellitus in 6 cases $(23 \%)$ and the order of diagnosis was unable to be identified in 8 cases (31\%) (Table 4). Patients were on Lugol solution, methimazole and propylthiouracil for the treatment of previously diagnosed GD. Compliance with anti-thyroid drugs was reported in 9 cases and all were

Table 3 Summary of laboratory results related to diagnostic criteria for diabetic ketoacidosis [1]

\begin{tabular}{llll}
\hline Name of investigation (unit) & Cases reported out of 26 (\%) & Range & Mean (SD) \\
\hline Anion gap (mmol/L) & $6(23)$ & $17.0-36.0$ & $27.8(7.0)$ \\
Arterial pH & $16(62)$ & $6.9-7.3$ & $7.2(0.1)$ \\
Effective serum osmolality $(\mathrm{mmol} / \mathrm{kg})$ & $6(23)$ & $282.2-339.0$ & $305.7(21.7)$ \\
Plasma glucose $(\mathrm{mmol} / \mathrm{L})$ & $24(92)$ & $18.7-48.5$ & $29.8(9.0)$ \\
Serum bicarbonate $(\mathrm{mmol} / \mathrm{L})$ & $17(65)$ & $2.8-17.0$ & $7.4(4.0)$ \\
\hline
\end{tabular}


Table 4 Order of diagnosis of diabetes mellitus and grave's disease, past treatment options and compliance

\begin{tabular}{|c|c|c|c|c|c|c|}
\hline Reference & $\begin{array}{l}\text { Order of diagnosis in the past } \\
\text { (Diabetes Mellitus and Grave's disease) }\end{array}$ & $\begin{array}{l}\text { Past anti-thyroid } \\
\text { treatment }\end{array}$ & $\begin{array}{l}\text { Anti-thyroid drug } \\
\text { compliance }\end{array}$ & $\begin{array}{l}\text { Past diabetes } \\
\text { treatment }\end{array}$ & $\begin{array}{l}\text { Diabetes drug } \\
\text { compliance }\end{array}$ & $\begin{array}{l}\text { Post presentation } \\
\text { diabetes type }\end{array}$ \\
\hline [10] & $\mathrm{T} 2 \mathrm{D} \rightarrow \mathrm{GD}$ & Methimazole & Poor & $\begin{array}{l}\text { Sulfonylurea, } \\
\text { thiazolidinedione }\end{array}$ & $\mathrm{N} / \mathrm{M}$ & $\mathrm{T} 2 \mathrm{D}$ \\
\hline [11] & GD & Methimazole & Poor & $\mathrm{N} / \mathrm{M}$ & N/M & $\mathrm{T} 1 \mathrm{D}$ \\
\hline [33] & GD & $\begin{array}{l}\text { Methimazole and } \\
\text { Lugol solution }\end{array}$ & Poor & $\mathrm{N} / \mathrm{M}$ & $\mathrm{N} / \mathrm{M}$ & IGT \\
\hline [34] & T2D, GD (Order not mentioned) & Methimazole & Poor & Insulin & Poor & $\mathrm{T} 2 \mathrm{D}$ \\
\hline [35] & Diabetes & $\mathrm{N} / \mathrm{M}$ & $\mathrm{N} / \mathrm{M}$ & $\mathrm{N} / \mathrm{M}$ & $\mathrm{N} / \mathrm{M}$ & $\mathrm{N} / \mathrm{M}$ \\
\hline [35] & Diabetes & $\mathrm{N} / \mathrm{M}$ & $\mathrm{N} / \mathrm{M}$ & $\mathrm{N} / \mathrm{M}$ & N/M & $\mathrm{N} / \mathrm{M}$ \\
\hline [35] & Diabetes & $\mathrm{N} / \mathrm{M}$ & $\mathrm{N} / \mathrm{M}$ & $\mathrm{N} / \mathrm{M}$ & N/M & $\mathrm{N} / \mathrm{M}$ \\
\hline [35] & Diabetes & $\mathrm{N} / \mathrm{M}$ & $\mathrm{N} / \mathrm{M}$ & $\mathrm{N} / \mathrm{M}$ & N/M & $\mathrm{N} / \mathrm{M}$ \\
\hline [35] & Diabetes & $\mathrm{N} / \mathrm{M}$ & $\mathrm{N} / \mathrm{M}$ & $\mathrm{N} / \mathrm{M}$ & $\mathrm{N} / \mathrm{M}$ & N/M \\
\hline [36] & N/M & $\mathrm{N} / \mathrm{M}$ & $\mathrm{N} / \mathrm{M}$ & $\mathrm{N} / \mathrm{M}$ & $\mathrm{N} / \mathrm{M}$ & $\mathrm{T} 1 \mathrm{D}$ \\
\hline [37] & GD & $\mathrm{N} / \mathrm{M}$ & Poor & $\mathrm{N} / \mathrm{M}$ & N/M & $\mathrm{T} 1 \mathrm{D}$ \\
\hline [38] & $\mathrm{T} 2 \mathrm{D}$ & $\mathrm{N} / \mathrm{M}$ & $\mathrm{N} / \mathrm{M}$ & Insulin & N/M & $\mathrm{T} 2 \mathrm{D}$ \\
\hline [39] & N/M & $\mathrm{N} / \mathrm{M}$ & $\mathrm{N} / \mathrm{M}$ & $\mathrm{N} / \mathrm{M}$ & N/M & $\mathrm{T} 1 \mathrm{D}$ \\
\hline [40] & N/M & $\mathrm{N} / \mathrm{M}$ & $\mathrm{N} / \mathrm{M}$ & $\mathrm{N} / \mathrm{M}$ & $\mathrm{N} / \mathrm{M}$ & $\mathrm{T} 2 \mathrm{D}$ \\
\hline [41] & $\mathrm{GD} \rightarrow \mathrm{T} 1 \mathrm{D}$ & Propylthiouracil & Poor & Insulin & $\mathrm{N} / \mathrm{M}$ & T1D \\
\hline [42] & $\mathrm{T} 2 \mathrm{D}$ & $\mathrm{N} / \mathrm{M}$ & N/M & $\mathrm{N} / \mathrm{M}$ & $\mathrm{N} / \mathrm{M}$ & $\mathrm{T} 2 \mathrm{D}$ \\
\hline [43] & $\mathrm{N} / \mathrm{M}$ & $\mathrm{N} / \mathrm{M}$ & $\mathrm{N} / \mathrm{M}$ & $\mathrm{N} / \mathrm{M}$ & $\mathrm{N} / \mathrm{M}$ & $\mathrm{T} 1 \mathrm{D}$ \\
\hline [44] & $\mathrm{GD} \rightarrow \mathrm{T} 1 \mathrm{D}$ & Anti-thyroid drug & Poor & Insulin & Poor & $\mathrm{T} 1 \mathrm{D}$ \\
\hline [45] & $\mathrm{T} 1 \mathrm{D} \rightarrow \mathrm{GD}$ & Propylthiouracil & Poor & Insulin & N/M & $\mathrm{T} 1 \mathrm{D}$ \\
\hline [46] & $\mathrm{T} 1 \mathrm{D}$ & $\mathrm{N} / \mathrm{M}$ & $\mathrm{N} / \mathrm{M}$ & Pre-mix insulin & N/M & $\mathrm{T} 1 \mathrm{D}$ \\
\hline [47] & $\mathrm{N} / \mathrm{M}$ & $\mathrm{N} / \mathrm{M}$ & $\mathrm{N} / \mathrm{M}$ & $\mathrm{N} / \mathrm{M}$ & N/M & $\mathrm{N} / \mathrm{M}$ \\
\hline [48] & N/M & $\mathrm{N} / \mathrm{M}$ & $\mathrm{N} / \mathrm{M}$ & $\mathrm{N} / \mathrm{M}$ & N/M & $\mathrm{T} 1 \mathrm{D}$ \\
\hline [48] & $\mathrm{N} / \mathrm{M}$ & $\mathrm{N} / \mathrm{M}$ & $\mathrm{N} / \mathrm{M}$ & $\mathrm{N} / \mathrm{M}$ & $\mathrm{N} / \mathrm{M}$ & $\mathrm{T} 1 \mathrm{D}$ \\
\hline [49] & T1D & $\mathrm{N} / \mathrm{M}$ & $\mathrm{N} / \mathrm{M}$ & $\mathrm{N} / \mathrm{M}$ & N/M & $\mathrm{T} 1 \mathrm{D}$ \\
\hline [50] & $\mathrm{T} 2 \mathrm{D}$ & $\mathrm{N} / \mathrm{M}$ & $\mathrm{N} / \mathrm{M}$ & $\begin{array}{l}\text { Glargine-insulin, aspart- } \\
\text { insulin, metformin }\end{array}$ & N/M & $\mathrm{T} 2 \mathrm{D}$ \\
\hline [51] & GD & $\mathrm{N} / \mathrm{M}$ & Poor & $\mathrm{N} / \mathrm{M}$ & N/M & T1D \\
\hline
\end{tabular}

GD Graves' disease, IGT Impaired glucose tolerance, N/M Not mentioned, T1D Type 1 diabetes mellitus, T2D Type 2 diabetes mellitus

reported to have poor compliance (Table 4). Patients were on insulin, metformin, sulfonylurea and thiazolidinedione for the treatment of previously diagnosed diabetes mellitus. Compliance with anti-diabetic drugs was reported in 2 cases and both were reported to have poor compliance (Table 4). Among the post presentation diabetes types, type 1 diabetes mellitus was diagnosed in 13 cases (50\%), type 2 diabetes mellitus in 6 cases (23\%), impaired glucose tolerance in 1 case (4\%) and the rest were not reported $(23 \%-6 / 26)$.

\section{Examination findings}

On examination, 77\% (20/26) had a thyroid goitre. Features of GD and dehydration were reported in 73\% (19/ $26)$ and $31 \%(8 / 26)$ respectively. Exophthalmos was seen in 8 cases out of which $50 \%$ were reported to have bilateral exophthalmos. Also, tremor was observed in 8 patients (31\%). Twenty-two (85\%) patients reported both systolic and diastolic blood pressure with a mean of 118.8 (SD 25.8) and 62.0 (SD 25.7) $\mathrm{mmHg}$ respectively. Moreover, respiratory rate was reported in 9 patients (35\%) with a mean of 25.4 (SD 6.4) breaths per minute. Further, Kussmaul breathing was observed in 31\% (8/ 26). Abdominal examination was reported in $35 \%(9 / 26)$, and none had positive findings.

\section{Treatment modalities and survival}

Symptom control of TS was achieved with beta blockers (69\% - 18/26) namely, propranolol (78\% - 14/18), landiolol, metoprolol, esmolol and practolol (each - 6\% - 1/18). Also, digoxin and reserpine were used in one case each. Thyroid hormone synthesis/release was decreased using antithyroid drugs, radioiodine, and surgery. Propylthiouracil (42\% - 11/ 26), methimazole $(31 \%-8 / 26)$ and carbimazole $(19 \%-5 / 26)$ 
were the thionamides used as anti-thyroid agents. However, the latest 4 cases had methimazole as the anti-thyroid agent. Moreover, iodide treatment was used in 16 patients (62\%) and steroids (hydrocortisone - 6, dexamethasone - 3) in 9 patients (35\%). Further, thyroidectomy was performed in 15\% $(4 / 26)$ of the reported cases.

Treatment for DKA included insulin with intravenous fluids which were received by all patients. Also, electrolyte replacement was received by $19 \%(5 / 26)$ and sodium bicarbonate by $4 \%(1 / 26)$. Seven patients were reported to have been maintained on insulin after discharge. Thionamide agents were reported to be continued in 4 patients after discharge (Additional file 1). Cardiovascular, renal and gastrointestinal complications were the top three complications (Table 5). Out of the 26 cases, all survived except four (15\%). The causes of death were focal bronchopneumonia with thyrotoxic storm [34], sepsis [35], acute respiratory distress syndrome [42] and multi-organ failure [47].

\section{Discussion}

The systematic review found only twenty-six cases globally for concurrent presentation of TS and DKA with a mortality rate of $15 \%$ which illustrate a rare but, potentially life-threatening condition. The presentation was common among females and in middle age. Female predominance was predictable as both TS and DKA are common among females $[3,7]$. Poor drug compliance is a common precipitating factor for both TS and DKA $[4,6]$. And, the review too revealed a poor compliance for routine anti-thyroid and anti-diabetic agents among reported cases. The above statement was further supported by elevated $\mathrm{HbA}_{1 \mathrm{C}}$ and T4 levels with a low TSH among all patients with reported measurements. Thus, the rare life-threatening concurrent presentation of TS and DKA

Table 5 Disabilities and complications experienced by the patients

\begin{tabular}{ll}
\hline System & $\begin{array}{l}\text { Frequency out of } \\
26(\%)\end{array}$ \\
\hline $\begin{array}{l}\text { Cardiovascular (acute pericarditis, cardiac } \\
\text { arrest, Takotsubo cardiomyopathy) }\end{array}$ & $5(19)$ \\
$\begin{array}{l}\text { Renal (anuria, perinephric abscess, renal } \\
\text { failure, urinary tract infection) }\end{array}$ & $4(15)$ \\
$\begin{array}{l}\text { Gastrointestinal tract (hepatopathy, liver failure) } \\
\text { Respiratory (H1N1, influenza B, respiratory failure) }\end{array}$ & $3(12)$ \\
$\begin{array}{l}\text { Haematology (disseminated intravascular } \\
\text { coagulation, thrombocytopenia) }\end{array}$ & $2(8)$ \\
$\begin{array}{l}\text { Metabolic (hyperuricemia, hypoproteinemia) } \\
\text { Neurological/ psychological (encephalopathy, } \\
\text { meningism) }\end{array}$ & $2(8)$ \\
General (hyperthermia) & $2(8)$ \\
Musculoskeletal (rhabdomyolysis) & $1(4)$ \\
\hline
\end{tabular}

is likely with poor drug compliance. Hence, it is essential to maximise patient compliance to anti-thyroid and anti-diabetic agents and monitor the disease control via laboratory tests. Moreover, both TS and DKA have similar predisposing factors $[6,52]$ therefore, a common trigger could have resulted in triggering them together. Although, most of the cases had a diagnosis of diabetes mellitus preceding that of GD, it was unclear if DKA preceded TS. Nevertheless, Potenza M and colleagues (2009) proposed an initial trigger by excessive thyroid hormone to cause DKA which would subsequently leads to TS [10].

The mean quality assessment score for the selected articles was 19.2 (SD \pm 3.6$)$ out of a total of 30 per article. Differences in reporting of clinical presentation, investigation findings and treatment options were noted. These limited the review in producing a comprehensive summary of the simultaneous development of TS and DKA. Prospective studies on concurrent presentation of TS and DKA are not possible due to the rare nature of the condition. However, constant reporting of similar cases is essential for the better understanding of this rare entity.

\section{Conclusions}

The concurrent presentation of TS with DKA is rare but can be life-threatening. Efforts should be made to maximise patient compliance to anti-thyroid and anti-diabetic agents to prevent the above concurrent presentation. Also, monitoring of the disease control should be supported by laboratory investigations. Identification of one entity should alert the treating clinician to look for features of the other entity. Hence, the early detection of the rare presentation could help optimize management with anti-thyroid drugs, insulin and intravenous fluids.

\section{Additional files}

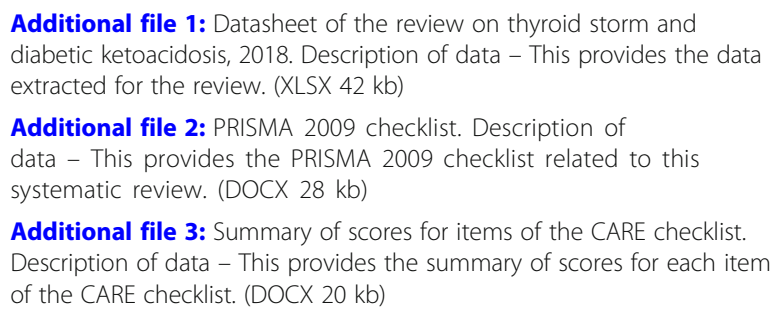

Additional file 3: Summary of scores for items of the CARE checklist. Description of data - This provides the summary of scores for each item of the CARE checklist. (DOCX $20 \mathrm{~kb}$ )

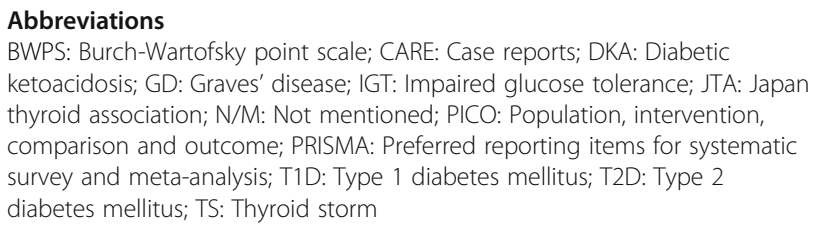




\section{Funding}

The study was self-funded.

\section{Availability of data and materials}

All data generated or analysed during this study are included in this published article (and its additional files).

\section{Authors' contributions}

DR conceived the idea and designed the review. Both DR and SK were involved in data collection. DR performed a comprehensive literature search. SK independently screened the titles and abstracts of all identified studies for selection, according to the inclusion criteria. The selected study was independently reviewed by DR to confirm the eligibility. Both DR and SK were involved in the writing of the manuscript. Both authors approved the final manuscript.

\section{Ethics approval and consent to participate}

Not applicable.

\section{Consent for publication}

Not applicable.

\section{Competing interests}

The authors declare that they have no competing interests.

\section{Publisher's Note}

Springer Nature remains neutral with regard to jurisdictional claims in published maps and institutional affiliations.

\section{Received: 28 January 2019 Accepted: 23 April 2019}

\section{Published online: 17 May 2019}

\section{References}

1. Kitabchi AE, Umpierrez GE, Miles JM, Fisher JN. Hyperglycemic crises in adult patients with diabetes. Diabetes Care. 2009;32(7):1335-43.

2. Kitabchi AE, Wall BM. Diabetic ketoacidosis. Med Clin North Am. 1995;79(1): 9-37.

3. Farsani SF, Brodovicz K, Soleymanlou N, Marquard J, Wissinger E, Maiese BA. Incidence and prevalence of diabetic ketoacidosis (DKA) among adults with type 1 diabetes mellitus (T1D): a systematic literature review. BMJ Open. 2017;7(7):e016587.

4. Umpierrez G, Korytkowski M. Diabetic emergencies - ketoacidosis, hyperglycaemic hyperosmolar state and hypoglycaemia. Nat Rev Endocrinol. 2016:12(4):222-32.

5. Galindo RJ, Hurtado CR, Pasquel FJ, García Tome R, Peng L, Umpierrez GE. National Trends in incidence, mortality, and clinical outcomes of patients hospitalized for thyrotoxicosis with and without thyroid storm in the United States, 2004-2013. Thyroid. 2019;29(1):36-43.

6. Pokhrel B, Bhusal K. Thyroid Storm StatPearls StatPearls Publishing LLC. 2018.

7. Chiha M, Samarasinghe S, Kabaker AS. Thyroid storm: an updated review. J Intensive Care Med. 2015;30(3):131-40.

8. Ono $Y$, Ono S, Yasunaga H, Matsui H, Fushimi K, Tanaka Y. Factors associated with mortality of thyroid storm: analysis using a National Inpatient Database in Japan. Medicine (Baltimore). 2016;95(7):e2848.

9. Akamizu T. Thyroid storm: a Japanese perspective. Thyroid. 2018;28(1):32-40.

10. Potenza M, Via MA, Yanagisawa RT. Excess thyroid hormone and carbohydrate metabolism. Endocr Pract. 2009;15(3):254-62.

11. Ikeoka T, Otsuka H, Fujita N, Masuda Y, Maeda S, Horie I, et al. Thyroid storm precipitated by diabetic ketoacidosis and influenza a: a case report and literature review. Intern Med. 2017;56(2):181-5.

12. Satoh T, Isozaki O, Suzuki A, Wakino S, Iburi T, Tsuboi K, et al. 2016 guidelines for the management of thyroid storm from the Japan thyroid association and Japan Endocrine Society (first edition). Endocr J. 2016;63(12): 1025-64.

13. Akamizu T, Satoh T, Isozaki O, Suzuki A, Wakino S, Iburi T, et al. Diagnostic criteria, clinical features, and incidence of thyroid storm based on Nationwide surveys. Thyroid. 2012;22(7):661-79.

14. PubMed [Internet]. 2018 [cited 2018 Sep 21]. Available from: https://www. ncbi.nlm.nih.gov/pubmed/advanced

15. Science Direct [Internet]. 2018 [cited 2018 Sep 21]. Available from: https:// www.sciencedirect.com/search/advanced
16. Trip Database [Internet]. 2018 [cited 2018 Sep 21]. Available from: https:// www.tripdatabase.com/

17. Cochrane Library [Internet]. 2018 [cited 2018 Sep 21]. Available from: http:// www.cochranelibrary.com/

18. Google Scholar [Internet]. 2018 [cited 2018 Sep 21]. Available from: https:// scholar.google.com/

19. Gagnier JJ, Kienle G, Altman DG, Moher D, Sox H, Riley D, et al. The CARE guidelines: consensus-based clinical case reporting guideline development. Glob Adv Heal Med. 2013;2(5):38-43.

20. Moher D, Liberati A, Tetzlaff J, Altman DG, PRISMA Group. Preferred reporting items for systematic reviews and meta-analyses: the PRISMA statement. PLoS Med. 2009;6(7):e1000097.

21. Burch HB, Wartofsky L. Life-threatening thyrotoxicosis. Thyroid storm. Endocrinol Metab Clin N Am. 1993;22(2):263-77.

22. Hessulf F, Håkansson D, Nilsson M, Ribom-Bornefalk E. Thyroid storm and diabetic ketoacidosis (DKA) in a previously healthy male - a significant differential diagnostic challenge. Lakartidningen. 2018;115(2):7-10.

23. Cikos J. Thyroid crisis associated with diabetic ketoacidosis. Report of a case. Srp Arh Celok Lek. 104(3-4):263-71.

24. Vetshev PS, Ippolitov LI, KOvalenko El. False acute abdomen in clinical practice. Klin Med (Mosk). 2003:81(2):20-7.

25. Starkova NT, Kazeev KN, Butrova SA. Emergency conditions in endocrinology. Ter Arkh. 1982;54(10):3-6.

26. Ito S, Tamura T, Adachi S, Seki K, Nishikawa M. Simultaneous development of thyroid crisis and diabetic acidosis in a patient treated with 131-I for hyperthyroidism. Naika. 1965;16(5):883-6.

27. Yamaguchi $K$, Fukushima H, Yano T, Kato N, Uzawa H. A case of thyroid storm associated with diabetic ketoacidosis (author's transl). Nihon Naibunpi Gakkai Zasshi. 1980;56(9):1223-30.

28. Bürgi U, Perrig M. Endocrine crises. Ther Umsch. 2005 Jun;62(6):369-73.

29. Grosser KD, Hŭbner W. Metabolic crises. Internist (Berl). 1975;16(3):99-107.

30. Maaz E. Concomitant occurrence of hyper-thyroid crisis and ketoacidotic diabetic coma. Z Gesamte Inn Med. 1974;29(12):498-503.

31. Menzel K, Hoffmann W. Basedow coma and diabetic ketoacidosis in a 13year-old girl. Kinderarztl Prax. 1971;39(10):445-50.

32. Lenhardt A. Simultaneous occurrence of a thyrotoxic crisis and diabetic acidosis presented as a diabetic pre-coma. Wien Med Wochenschr. 1963; 113:680-2.

33. Hanscom DH, Ryan RJ. Thyrotoxic crisis and diabetic ketoacidosis; report of a case. N Engl J Med. 1957:257(15):697-701.

34. Kunishige $M$, Sekimoto $E$, Komatsu $M$, Bando $Y$, Uehara H, Izumi K. Thyrotoxicosis masked by diabetic ketoacidosis: a fatal complication. Diabetes Care. 2001;24(1):171.

35. Lakin M, Bradley RF, Bell GO. Acute hyperthyroidism in severe diabetic ketoacidosis. Am J Med Sci. 1961;241:443-7.

36. Lim D, Lunt H, Ojala R, Turner J. Simultaneous presentation of type 1 diabetes and thyrotoxicosis as a medical emergency. N Z Med J. 2004 117(1189):U775

37. Lin C-H, Chen S-C, Lee C-C, Ko PC-I, Chen W-J. Thyroid storm concealing diabetic ketoacidosis leading to cardiac arrest. Resuscitation. 2004:63(3):345-7.

38. Memon R, Fan W, Snyder R, Krishnamurthy M. Thyroid storm presenting as psychosis: masked by diabetic ketoacidosis. J community Hosp Intern Med Perspect. 2016;6(4):31750.

39. Noh BH, Cho S-W, Ahn SY. Simultaneous occurrence of diabetic ketoacidosis, thyroid storm, and multiple cerebral infarctions due to Moyamoya disease. J Pediatr Endocrinol Metab. 2016;29(2):221-5.

40. Osada E, Hiroi N, Sue M, Masai N, Iga R, Shigemitsu R, et al. Thyroid storm associated with graves' disease covered by diabetic ketoacidosis: a case report. Thyroid Res. 2011;4(1):8.

41. Solá E, Morillas C, Garzón S, Gómez-Balaguer M, Hernández-Mijares A. Association between diabetic ketoacidosis and thyrotoxicosis. Acta Diabetol. 2002;39(4):235-7.

42. Wu W-T, Hsu P-C, Huang H-L, Chen Y-C, Chien S-C. A case of Takotsubo cardiomyopathy precipitated by thyroid storm and diabetic ketoacidosis with poor prognosis. Acta Cardiol Sin. 2014;30(6):574-7.

43. Ahmad F, Mukhopadhyay B. Simultaneous presentation of type 1 diabetes and graves' disease. Scott Med J. 2011;56(1):1-2.

44. Yeo K-F, Yang Y-S, Chen K-S, Peng C-H, Huang C-N. Simultaneous presentation of thyrotoxicosis and diabetic ketoacidosis resulted in sudden cardiac arrest. Endocr J. 2007;54(6):991-3. 
45. Ahmad N, Cohen M. Thyroid storm with Normal serum triiodothyronine level during diabetic ketoacidosis. JAMA J Am Med Assoc. 1981;245(24):2516.

46. Alshareef MA, Bokhari S, El Saoud H, Khan P. Severe diabetic ketoacidosis and acute pericarditis precipitated by concomitant graves' thyrotoxicosis in type 1 diabetic patient. J Heal Spec. 2014;2(4):177.

47. Baharoon S. H1N1 infection-induced thyroid storm. Ann Thorac Med. 2010; 5(2):110.

48. Bridgman JF, Pett S. Simultaneous presentation of thyrotoxic crisis and diabetic ketoacidosis. Postgrad Med J. 1980;56(655):354-5.

49. Cheng E, Chen T, Lin C, Chen R. Concurrent presentation of diabetic ketoacidosis and thyrotoxicosis in a diabetic patient. Resusc Intensive Care Med. 2017;2:95-8.

50. Eliades M, El-Maouche D, Choudhary C, Zinsmeister B, Burman KD. Takotsubo cardiomyopathy associated with thyrotoxicosis: a case report and review of the literature. Thyroid. 2014;24(2):383-9.

51. Gupta S, Kandpal SB. Case report: storm and acid, together... ! Am J Med Sci. 2011;342(6):533-4

52. Umpierrez GE, Kitabchi AE. Diabetic ketoacidosis: risk factors and management strategies. Treat Endocrinol. 2003;2(2):95-108.

Ready to submit your research? Choose BMC and benefit from:

- fast, convenient online submission

- thorough peer review by experienced researchers in your field

- rapid publication on acceptance

- support for research data, including large and complex data types

- gold Open Access which fosters wider collaboration and increased citations

- maximum visibility for your research: over $100 \mathrm{M}$ website views per year

At $\mathrm{BMC}$, research is always in progress.

Learn more biomedcentral.com/submissions 